\title{
Illness, medical expenditure and household consumption: observations from Taiwan
}

\author{
Kuangnan Fang ${ }^{1}$, Chi Ma², Yefei Jiang ${ }^{1}$, Linglong Ye ${ }^{1}$, Benchang Shia ${ }^{1,3}$ and Shuangge $\mathrm{Ma}^{1,3,4^{*}}$
}

\begin{abstract}
Background: Illness conditions lead to medical expenditure. Even with various types of medical insurance, there can still be considerable out-of-pocket costs. Medical expenditure can affect other categories of household consumptions. The goal of this study is to provide an updated empirical description of the distributions of illness conditions and medical expenditure and their associations with other categories of household consumptions.

Methods: A phone-call survey was conducted in June and July of 2012. The study was approved by ethics review committees at Xiamen University and FuJen Catholic University. Data was collected using a Computer-Assisted Telephone Survey System (CATSS). "Household" was the unit for data collection and analysis. Univariate and multivariate analyses were conducted, examining the distributions of illness conditions and the associations of illness and medical expenditure with other household consumptions.

Results: The presence of chronic disease and inpatient treatment was not significantly associated with household characteristics. The level of per capita medical expenditure was significantly associated with household size, income, and household head occupation. The presence of chronic disease was significantly associated with levels of education, insurance and durable goods consumption. After adjusting for confounders, the associations with education and durable goods consumption remained significant. The presence of inpatient treatment was not associated with consumption levels. In the univariate analysis, medical expenditure was significantly associated with all other consumption categories. After adjusting for confounding effects, the associations between medical expenditure and the actual amount of entertainment expenses and percentages of basic consumption, savings, and insurance (as of total consumption) remained significant.

Conclusion: This study provided an updated description of the distributions of illness conditions and medical expenditure in Taiwan. The findings were mostly positive in that illness and medical expenditure were not observed to be significantly associated with other consumption categories. This observation differed from those made in some other Asian countries and could be explained by the higher economic status and universal basic health insurance coverage of Taiwan.
\end{abstract}

Keywords: Illness, Medical expenditure, Household consumption, Taiwan

\section{Background}

Illness conditions incur medical expense. Multiple studies have shown that medical expenses can have a far-reaching impact on other categories of consumptions [1-4]. The underlying mechanism is simple: with a fixed total budget, when medical expense occurs, individuals and households can be forced to reduce other consumptions, including,

\footnotetext{
* Correspondence: shuangge.ma@yale.edu

'Department of Statistics, Xiamen University, Xiamen, China

${ }^{3}$ Department of Statistics and Information Science, FuJen Catholic University, New Taipei, Taiwan

Full list of author information is available at the end of the article
}

for example, food, education, farming expenses, other production means, recreation, and others. Such reductions have been observed in multiple studies [5,6], and may have a significant long-term impact.

Taiwan is a state in East Asia. A map is shown in Figure 1. In 2012, the estimated population was about 23 million. It has a relatively higher economic status than many other Asian regions and countries. Its 2011 estimated per capita GDP (PPP) was $\$ 37,719$, which ranked it $19^{\text {th }}$ in the world and $8^{\text {th }}$ in Asia. Taiwan's 2011 estimated per capita nominal GDP was $\$ 20,100$,

\section{Biomed Central}

(c) 2013 Fang et al.; licensee BioMed Central Ltd. This is an Open Access article distributed under the terms of the Creative Commons Attribution License (http://creativecommons.org/licenses/by/2.0), which permits unrestricted use, distribution, and reproduction in any medium, provided the original work is properly cited. 


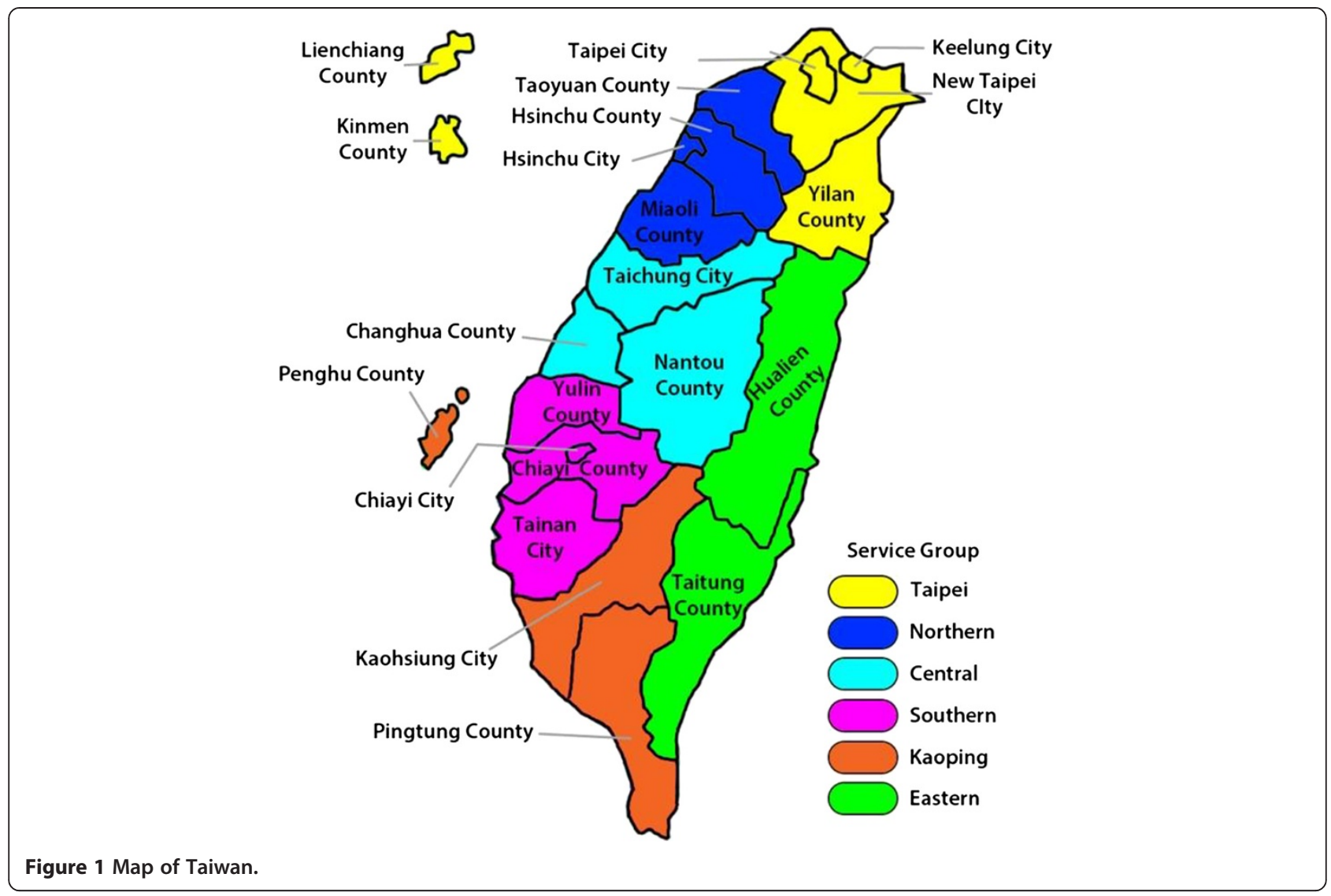

which ranked it $39^{\text {th }}$. Taiwan is one of the few countries/ regions that offer universal health insurance coverage, which has been applauded as one of the most successful and made Taiwan significantly different from most other Asian countries.

In the literature, there are a large number of studies on illness conditions and health sector performance in Taiwan [7-12]. However, our literature review suggested that most studies had been focused on illness conditions and research questions related to health insurance (coverage, cost, effects, etc.). There is a lack of research on the associations of illness and medical expenditure with the overall expenditure structure.

Studies on the relationship between medical expenditure and other types of expenditures have been reported for other Asian countries. For example, the study conducted by Nguyen and others [13] reported the impact of medical expenditure in rural Vietnam, where the per capita income was about $\$ 630$. It was observed that households with at least one inpatient treatment and/or higher levels of outpatient treatments had significantly reduced consumptions of basic capacities including food, education, and production means. Setboonsarng and Lavado [6] reached a similar conclusion from a study conducted in rural Thailand, where the total household expenditure per year was about $\$ 1,723$. (Average house- hold size was not reported). The study by Wang and others [5] analyzed a community-based survey conducted in poor, rural areas of mainland China in 2002. It was suggested that "medical expenditure reduced household investment in human capital, physical capital for farm production, and other consumptions that are critical to human well-being" [5].

Our main goal is to provide an updated empirical description of the associations of illness conditions and medical expenditure with other types of expenditures in Taiwan. This objective is similar to that of several published studies [5,13]. However, different from other regions studied in the literature $[5,6,13]$, Taiwan has a much higher economic status and offers universal health insurance coverage. Thus observations are expected to be different, and so this study is warranted beyond the published ones.

\section{Methods}

Study design and data collection

This study was approved by research ethics review committees at Xiamen University in China and FuJen Catholic University in Taiwan (IRB approval forms available upon request).

The study was designed to cover all major areas of Taiwan. The Taiwan Bureau of National Health Insurance 
classified the 22 counties and cities into six regions called "service groups" (see Figure 1). The Taipei service group includes Taipei, Keelung New Taipei, Yilan, Kinmen, and Liechiang. The northern group includes Hsinchu County, Hsinchu City, Taoyuan, and Miaoli. The central service group includes Taichung, Nantou, and Changhua. The southern service group includes Tainan, Yunlin, Chiayi County, and Chiayi City. The Kaoping service group includes Kaohsiung, Pingtung, and Penghu. The eastern service group includes Hualien and Taitung.

The survey was conducted by staff at the Data Mining Research Center (DMRC) at Xiamen University in China in June and July of 2012. A Computer-Assisted Telephone Survey System (CATSS) was utilized. Phone numbers used for the survey were obtained from Chunghwa Telecom Co., Ltd., and Taiwan Cellular Co., Ltd., and included both landlines and cell phones. Samples were collected using an RDD (random digit dialing) approach. Specifically, this study used Mitofsky-Waksberg-type samples of active blocks of 100 consecutive phone numbers from all possible such blocks within each city and county [14]. The probability of a block's initial selection was proportional to the block's 100 numbers that served individuals and residences. The survey database was updated after each phone call to ensure that no household was sampled more than once.

For each survey, information was first collected to determine inclusion. A household would be excluded if (a) the interviewee refused to participate, (b) the interviewee was less than 18 years old, (c) the interviewee could not provide reliable information on the household, or (d) the interviewee did not live in Taiwan for over six months a year. For each surveyed household, verbal consent was obtained and recorded. The survey included both "snapshot" questions (including, for example, demographic information and insurance status) and "accumulation" questions (such as income and expenses over a period of 12 months prior to the survey). On average, one survey took about ten minutes. Data on 2,607 households was collected. The overall survey response rate was $41.2 \%$.

\section{Statistical analysis}

As "household" remained the basic functional unit for income and expenses, analysis was conducted at the household level. Raw data was examined using various graphical approaches, and no obviously unreasonable measurement was observed. In the first set of analyses, the associations of illness conditions (measured by the presence of chronic disease and inpatient treatment) and medical expenses with household and household head characteristics were examined. The differences between different illness and medical expense groups were quantified using t-tests for continuous variables and chi-squared tests for categorical variables. A similar approach was employed to study the associations between illness and consumptions in the univariate analysis. Multivariate analysis was then conducted, adjusting for the confounding effects of household and household head characteristics. In order to get a comprehensive description, each consumption category was analyzed separately. With a similar strategy, the associations between medical expenditure and other types of consumptions were also analyzed directly. In the analysis of expenditure structure, two sets of analyses were conducted. In the first set, the actual amount of consumption was analyzed. Here, the response variable was continuous, and linear regression was adopted. In the second set of analyses, the percentage of each category of consumption (as of total consumption) was analyzed using logistic-type regression. Model diagnostics were conducted using various graphical tools. The analysis was conducted using $\mathrm{R}$ software Version 2.15.1 (www.r-project.org).

\section{Results \\ Characteristics of illness conditions and medical expenditure}

Table 1 presents summary statistics of household and household head characteristics for the whole cohort and subgroups with different illness conditions and medical expenditure levels. Two measurements were used for illness conditions. The first was the presence of members with chronic diseases, which were long-term and had multiple episodes and low cost per episode. The second was the presence of members with inpatient treatments, which had a low frequency but high cost per episode. There were 1,566 households $(60 \%)$ with the presence of chronic diseases and 1,540 households (59.1\%) with the presence of inpatient treatments in 12 months. Medical expenditure was defined as the per capita, out-of-pocket medical expense accumulated over a period of 12 months. Expenditure data was collected at the household level and then normalized by household size. Taiwan has an effective health insurance system with a low copayment, which has a ceiling and can be completely waived under certain circumstances. Thus, out-of-pocket cost and gross cost can be significantly different. Here, the focus is on out-ofpocket cost, which is a practically more meaningful measure for households. The continuous medical expenses were dichotomized at the median $(57,000 \mathrm{NT}$, which is $1,906.63 \mathrm{USD}$ under the exchange rate $1 \mathrm{USD}=29.851 \mathrm{NT}$ ) to create "high"- and "low"-cost groups.

Table 1 suggests that the distribution of illness conditions is not significantly associated with household characteristics (including household size, number of members younger than 18 , number of members older than 65 , public health insurance coverage, private health insurance coverage, location, and income) and household head characteristics (including age, gender, education, marital status, 
Table 1 Characteristics of the whole cohort and subgroups with different illness conditions and medical expense levels

\begin{tabular}{|c|c|c|c|c|c|c|c|}
\hline \multirow[b]{2}{*}{ Variables } & \multirow[b]{2}{*}{ Whole cohort } & \multicolumn{2}{|c|}{ Presence of chronic disease } & \multicolumn{2}{|c|}{ Presence of inpatient treatment } & \multicolumn{2}{|c|}{ Medical expense } \\
\hline & & Yes & No & Yes & No & High & Low \\
\hline
\end{tabular}

Data on household

Household size

$$
\text { p-value }
$$

Younger than $18^{*}$

$\begin{array}{cc}0 & 11.12 \\ 1 & 77.37 \\ 2 & 8.21 \\ 3 & 2.57 \\ 4 & 0.46 \\ 5 & 0.23 \\ 6 & 0.04 \\ \text { p-value } & \end{array}$

Older than $65^{*}$

$\begin{array}{cc}0 & 69.97 \\ 1 & 23.21 \\ 2 & 5.56 \\ 3 & 0.5 \\ 4 & 0.58 \\ 5 & 0.19 \\ \end{array}$

Public insurance coverage* 91.16 (19.14)

$$
\text { p-value }
$$

Private insurance coverage* $90.68(18.40)$ p-value

Location*

$$
\begin{gathered}
\text { Taipei } \\
\text { Northern } \\
\text { Central } \\
\text { Southern } \\
\text { Kaoping } \\
\text { Eastern } \\
\text { p-value }
\end{gathered}
$$$$
\text { Southern }
$$

Income

$\begin{aligned} & 17283 \\ & (6950)\end{aligned}$

$$
\text { p-value }
$$

\begin{tabular}{|c|c|}
\hline 70.24 & 69.55 \\
\hline 22.29 & 24.59 \\
\hline 5.94 & 5 \\
\hline 0.7 & 0.19 \\
\hline 0.64 & 0.48 \\
\hline 0.19 & 0.19 \\
\hline & \\
\hline
\end{tabular}

Data on household head

Age*

$$
\begin{gathered}
<20 \\
21-30 \\
31-40
\end{gathered}
$$

32.72
16.88
17.38
14.46
15.42
3.15

17283

6950)

(7125)
91.20 (19.21) $91.09(19.04)$

0.881

90.46 (18.9) 91.01 (17.5) 0.447

$\begin{array}{ll}33.27 & 31.89 \\ 16.91 & 16.91 \\ 16.54 & 18.64 \\ 14.81 & 13.93 \\ 15.33 & 15.56 \\ 3.19 & 3.07 \\ & 0.801 \\ 17132 & \\ (7125) & 17510 \\ & (6674)\end{array}$

0.168

69.55

0.48

11.24
78.29
7.4
2.11
0.58
0.29
0.1

8.29

2.11

0.58

1

(5)

(2)


Table 1 Characteristics of the whole cohort and subgroups with different illness conditions and medical expense levels (Continued)

\begin{tabular}{|c|c|c|c|c|c|c|c|}
\hline $41-50$ & 36.59 & 37.16 & 35.73 & 37.08 & 35.9 & 37.74 & 35.45 \\
\hline $51-60$ & 39.62 & 40.36 & 38.52 & 39.81 & 39.36 & 37.89 & 41.35 \\
\hline$>60$ & 10.36 & 10.03 & 10.85 & 10.19 & 10.59 & 9.99 & 10.72 \\
\hline$p$-value & & \multicolumn{2}{|c|}{0.318} & \multicolumn{2}{|c|}{0.691} & \multicolumn{2}{|c|}{0.272} \\
\hline
\end{tabular}

Gender*

$\begin{array}{ccccc}\text { Male } & 61.80 & 61.94 & & 61.58 \\ \text { p-value } & & & 0.883 & \end{array}$

0.925

61.95

$\begin{array}{lr}60.88 & 62.71 \\ 0.356 & \end{array}$

Education*

$\begin{array}{cc}<\text { Middle school } & 18.26 \\ \text { High school } & 34.79 \\ \text { Bachelor } & 38.36 \\ \text { >Bachelor } & 8.59 \\ \text { D-value } & \end{array}$

$\begin{array}{cr}19.16 & 16.91 \\ 34.42 & 35.35 \\ 38.38 & 38.33 \\ 8.05 & 9.41 \\ & 0.354\end{array}$

$\begin{array}{ccc}18.12 & & 18.46 \\ 33.77 & 36.27 \\ 39.09 & & 37.3 \\ 9.03 & 7.97 \\ & 0.470 & \end{array}$

$\begin{array}{ccc}17.29 & 19.22 \\ 35.59 & 34 \\ 38.28 & 38.44 \\ 8.84 & 8.35 \\ & 0.576 & \end{array}$

Marital status*

\begin{tabular}{cc} 
Single & 16.92 \\
Married & 68.66 \\
Divorced & 8.17 \\
Widowed & 6.25 \\
p-value & \\
\hline * &
\end{tabular}

$\begin{array}{lll}17.11 & & 16.62 \\ 67.5 & 70.41 \\ 8.43 & & 7.78 \\ 6.96 & & 5.19 \\ & 0.228 & \end{array}$

16.62
70.41
7.78
5.19

16.88
69.55
7.73

16.

$\begin{array}{ccc}16.96 & 16.22 & 17.61 \\ 67.39 & 69.1 & 68.22 \\ 8.81 & 8.15 & 8.19 \\ 6.84 & 6.53 & 5.97 \\ & & 0.765 \\ & & \end{array}$

\section{Occupation*}

\begin{tabular}{cccc} 
Government & 17.18 & 16.48 & 18.25 \\
State-owned Co & 11.93 & 12.45 & 11.14 \\
Private Co & 37.63 & 36.72 & 39 \\
Self-employed & 19.52 & 19.86 & 19.02 \\
Farmer & 8.52 & 8.43 & 8.65 \\
Unemployed & 2.07 & 2.55 & 1.34 \\
Retired & 2.57 & 3 & 1.92 \\
Other & 0.58 & 0.51 & 0.67 \\
p-value & & & 0.152 \\
\hline
\end{tabular}

Note: Values presented are mean (standard deviation) or percentage for variables marked by *. Income values are in USD.

and occupation). Such an observation is positive in the sense that socioeconomically less advantaged households - for example, those with lower incomes or living in less developed areas - were not more likely to suffer from illness. The level of per capita medical expense was positively associated with household size ( $\mathrm{p}$-value $<0.001$ ) and number of household members older than 65 (p-value 0.029). For example, $66.95 \%$ of households in the high expense group had no member older than 65, whereas that percentage was $72.97 \%$ in the low expense group. Medical expense was also positively associated with income ( $\mathrm{p}$-value $<0.001)$. Another factor significantly associated with medical expense level was household head occupation. Households with high expenses were more clustered in the "private company" and "self-employed" groups, whereas the low expense group was more evenly distributed. Similar associations between medical expenses and household size, income, and occupation have been observed in the literature $[5,9,13]$.

\section{Associations of illness conditions with consumption}

Nine categories of consumption were considered. More details are available in Table 2. Each category was computed as the per capita consumption accumulated over a period of 12 months. In the preliminary study, we found that households might purchase food, daily goods, clothes, and a few other items together and had trouble recalling the exact cost of each item. Thus, different from some existing studies [5], the category "basic consumption" was created to include food, clothes, 
Table 2 Per capita consumption of the whole cohort and households with different illness conditions and medical expense levels

\begin{tabular}{|c|c|c|c|c|c|c|c|}
\hline \multirow[b]{2}{*}{ Variables } & \multirow[b]{2}{*}{ Whole cohort } & \multicolumn{2}{|c|}{ Presence of chronic disease } & \multicolumn{2}{|c|}{ Presence of inpatient treatment } & \multicolumn{2}{|c|}{ Medical expense } \\
\hline & & Yes & No & Yes & No & High & Low \\
\hline \multicolumn{8}{|l|}{ Amount of expense (USD) } \\
\hline Basic (food, produce, etc.) & 3982.5 & 3934.7 & 4504.5 & 3992.1 & 3968.6 & 4716.9 & 3250.9 \\
\hline sd & 2020.3 & 2029.8 & 2004.7 & 2045.4 & 1984.3 & 2119.8 & 1612.6 \\
\hline$p$-value & & \multicolumn{2}{|c|}{0.137} & \multicolumn{2}{|c|}{0.769} & \multicolumn{2}{|c|}{$<0.001$} \\
\hline Education & 691.0 & 680.6 & 706.6 & 690.8 & 691.3 & 819.6 & 562.9 \\
\hline sd & 304.7 & 306.3 & 301.8 & 301.3 & 309.7 & 310.2 & 238.1 \\
\hline$p$-value & & \multicolumn{2}{|c|}{0.033} & \multicolumn{2}{|c|}{0.968} & \multicolumn{2}{|c|}{$<0.001$} \\
\hline Saving/Investment & 2960.0 & 2042.3 & 2986.7 & 2978.8 & 2933.0 & 3509.6 & 2412.6 \\
\hline sd & 1339.7 & 1363.3 & 1303.5 & 1333.8 & 1348.4 & 1370.6 & 1054.5 \\
\hline$p$-value & & \multicolumn{2}{|c|}{0.403} & \multicolumn{2}{|c|}{0.392} & \multicolumn{2}{|c|}{$<0.001$} \\
\hline Entertainment & 689.1 & 682.4 & 699.3 & 691.4 & 685.9 & 819.2 & 559.5 \\
\hline $\mathrm{sd}$ & 302.4 & 308.5 & 292.8 & 298.4 & $3-8.1248$ & 307.2 & 234.3 \\
\hline$p$-value & & \multicolumn{2}{|c|}{0.158} & \multicolumn{2}{|c|}{0.649} & \multicolumn{2}{|c|}{$<0.001$} \\
\hline Insurance & 1977.7 & 1945.9 & 2025.6 & 1989.5 & 1960.7 & 2345.0 & 1611.8 \\
\hline sd & 1004.6 & 1008.5 & 997.3 & 1006.5 & 1002.1 & 1045.0 & 811.9 \\
\hline p-value & & \multicolumn{2}{|c|}{0.047} & \multicolumn{2}{|c|}{0.472} & \multicolumn{2}{|c|}{$<0.001$} \\
\hline Durable goods & 398.0 & 389.7 & 410.4 & 400.6 & 394.1 & 470.5 & 325.7 \\
\hline sd & 198.4 & 196.9 & 200.1 & 194.9 & 203.4 & 205.3 & 161.8 \\
\hline$p$-value & & \multicolumn{2}{|c|}{0.009} & \multicolumn{2}{|c|}{0.415} & \multicolumn{2}{|c|}{$<0.001$} \\
\hline Alcohol/Tobacco & 196.3 & 193.7 & 200.1 & 196.9 & 195.4 & 233.8 & 159.0 \\
\hline sd & 100.7 & 102.7 & 97.6 & 101.1 & 100.1 & 106.6 & 78.3 \\
\hline$p$-value & & \multicolumn{2}{|c|}{0.108} & \multicolumn{2}{|c|}{0.717} & \multicolumn{2}{|c|}{$<0.001$} \\
\hline Other & 11.8 & 12.1 & 11.3 & 9.1 & 15.7 & 4.1 & 19.5 \\
\hline sd & 103.2 & 109.9 & 92.4 & 101.1 & 106.1 & 72.2 & 126.4 \\
\hline $\mathrm{p}$-value & & & & & & & \\
\hline Percentage of expense & & & & & & & \\
\hline Basic (food, produce, etc.) & 30.89 & 30.86 & 30.93 & 30.82 & 31.00 & 30.16 & 32.01 \\
\hline Education & 5.36 & 5.34 & 5.39 & 5.33 & 5.40 & 5.24 & 5.54 \\
\hline Saving/Investment & 22.96 & 23.08 & 22.79 & 22.99 & 22.91 & 22.44 & 23.76 \\
\hline Entertainment & 5.34 & 5.35 & 5.34 & 5.34 & 5.36 & 5.24 & 5.51 \\
\hline Insurance & 15.34 & 15.26 & 15.45 & 15.36 & 15.31 & 14.99 & 15.87 \\
\hline Durable goods & 3.09 & 3.06 & 3.13 & 3.09 & 3.08 & 3.01 & 3.21 \\
\hline Alcohol/Tobacco & 1.52 & 1.52 & 1.53 & 1.52 & 1.53 & 1.49 & 1.57 \\
\hline Other & 0.09 & 0.10 & 0.09 & 0.07 & 0.12 & 0.03 & 0.19 \\
\hline
\end{tabular}

Notes: Basic consumption includes food (rice, meet, vegetable, fruit, etc.), clothes, production means (farming equipment, fertilizer, seed, etc.), utilities (electricity, water, heating, cooking, renting, etc.), and daily goods (toiletries, kitchen supplies, etc.). Education includes tuition, book, and other education-related expenses. Saving/investment include banking and stock. Entertainment includes entertainment, travel, holidays, and other social activities. Insurance: for property, farm product, health, etc. Durable goods include furniture and electronic devices. Alcohol/Tobacco: cigarette, tobacco, wine, and liqueur. Medical expense: outpatient and inpatient services, drugs. Other: expenses not listed above.

production means, utilities, and daily goods. For the whole cohort, the biggest consumption category was basic consumption (30.89\%), followed by saving/investment (22.96\%), medical expense (15.41\%), and insurance (15.34\%).
The associations between illness conditions and consumptions were investigated using univariate analysis (Table 2) and multivariate analysis (Table 3). In the multivariate analysis, confounding effects of household and household head characteristics were adjusted for 
Table 3 Multivariate regression analysis: effects of the presence of chronic disease and inpatient treatment on expense, measured by actual amount (in USD) and percentage

\begin{tabular}{|c|c|c|c|c|c|c|c|c|}
\hline & \multicolumn{4}{|c|}{ Amount of expense } & \multicolumn{4}{|c|}{ Percentage of expense } \\
\hline & \multicolumn{2}{|c|}{$\begin{array}{c}\text { Presence of chronic } \\
\text { disease }\end{array}$} & \multicolumn{2}{|c|}{$\begin{array}{c}\text { Presence of inpatient } \\
\text { treatment }\end{array}$} & \multicolumn{2}{|c|}{$\begin{array}{c}\text { Presence of chronic } \\
\text { disease }\end{array}$} & \multicolumn{2}{|c|}{$\begin{array}{c}\text { Presence of inpatient } \\
\text { treatment }\end{array}$} \\
\hline & Regression coef & P-value & Regression coef & P-value & OR & P-value & OR & P-value \\
\hline Basic (food, produce, etc.) & -31.038 & 0.530 & -2.133 & 0.965 & 0.997 & 0.847 & 0.986 & 0.297 \\
\hline Education & -10.630 & 0.031 & -5.788 & 0.237 & 0.991 & 0.275 & 0.990 & 0.204 \\
\hline Medical expense & 4.621 & 0.851 & 29.990 & 0.221 & 1.015 & 0.285 & 1.020 & 0.142 \\
\hline Saving/Investment & 19.990 & 0.420 & 21.340 & 0.386 & 1.010 & 0.323 & 1.007 & 0.469 \\
\hline Entertainment & -1.616 & 0.744 & 0.229 & 0.963 & 0.999 & 0.891 & 0.998 & 0.784 \\
\hline Insurance & -36.236 & 0.150 & 14.187 & 0.571 & 0.986 & 0.299 & 1.003 & 0.811 \\
\hline Durable goods & -11.960 & 0.014 & 3.455 & 0.473 & 0.979 & 0.102 & 1.013 & 0.334 \\
\hline Alcohol/Tobacco & -1.923 & 0.447 & -0.099 & 0.969 & 0.980 & 0.144 & 0.993 & 0.594 \\
\hline
\end{tabular}

Notes: Adjusted for household characteristics (size, presence of member(s) younger than 18, presence of member(s) older than 65 , basic insurance coverage, commercial insurance coverage, city, urban, and income) and household head characteristics (age, gender, education, occupation, and marital status).

(with more details provided in Table 3). Two sets of analyses were conducted. The first set regressed the actual amount of each type of expense (in USD) on illness conditions and confounders, using linear regression. The second set was on the percentage of each category of expense (as of total expense). As the percentage lied between zero and one, logistic-type regression analysis was conducted [15]. Since the number of households that reported "other expense" was small and the actual amount was also small, this expense category was not analyzed.

The multivariate analysis suggests that, compared to those without chronic disease, households with chronic diseases had lower levels of expenses on education (an estimated difference of 10.63USD, p-value 0.031) and durable goods (an estimated difference of 11.96USD, p-value 0.014). The presence of inpatient treatment was not significantly associated with expense amount. Both the presence of chronic disease and inpatient treatment were not significantly associated with the percentages of expenses (as of total expense).

\section{Associations of medical expense with other expenses}

Other types of expenses were regressed on medical expense, adjusting for possible confounding effects. More details are provided in Table 4. Two sets of analyses were conducted, with one on the actual amount of consumption and the other on percentage. In the first set of analyses, only the association between medical expense and entertainment expense was statistically significant (p-value 0.049), with an increase in medical expense associated with a small (practically ignorable) increase in entertainment expense. In the analysis of percentage of expense, an increase in medical expense was significantly associated with a decrease in the percentage of basic consumption (with an odds ratio of 0.986, p-value $<0.001$ ), an increase in saving/investment (with an odds ratio of 1.020, p-value $<0.001$ ), and a decrease in insurance (with an odds ratio of $0.974, \mathrm{p}$-value $<0.001$ ). A significant change in the expenditure structure was observed, although the magnitudes of change measured by the odds ratios were small.

\section{Discussion}

Our survey showed that a considerable number of households suffered from illness. It is noted that, in this study, the presence of chronic disease and inpatient treatment was measured at the household level. Of the respondents, $59.1 \%$ of the households had inpatient treatments, which might seem high. In our preliminary study, we found that very few households had multiple members who had inpatient treatments. As the average household size was 4.72 , the percentage of household members who had inpatient treatment could be reasonable. In addition, this inpatient treatment rate is

Table 4 Multivariate regression analysis: impact of medical expense on other household expenses, measured by both actual amount and percentage

\begin{tabular}{lcccccc}
\hline & \multicolumn{2}{c}{ Actual amount } & & \multicolumn{2}{c}{ Percentage } \\
\cline { 2 - 3 } & Regression coef & P-value & & OR & P-value \\
\hline Basic (food, produce, etc.) & 0.025 & 0.530 & & 0.986 & $<0.001$ \\
Education & -0.003 & 0.450 & & 0.903 & 0.239 \\
Saving/Investment & 0.012 & 0.528 & & 1.020 & $<0.001$ \\
Entertainment & 0.008 & 0.049 & & 0.835 & 0.109 \\
Insurance & -0.026 & 0.192 & & 0.974 & $<0.001$ \\
Durable goods & -0.002 & 0.646 & & 0.996 & 0.169 \\
Alcohol/Tobacco & 0.002 & 0.388 & & 1.000 & 0.832 \\
\hline
\end{tabular}

Notes: Adjusted for household characteristics (size, presence of member(s) younger than 18 , presence of member(s) older than 65 , basic insurance coverage, commercial insurance coverage, city, urban, and income) and household head characteristics (age, gender, education, occupation, and marital status). 
comparable to that in a recent study conducted in the mainland China [16], which has population health characteristics comparable to those in Taiwan.

Consumption patterns observed in this study are significantly different from those in some other published studies. For example, in the study by Wang and others [5], medical expense accounted for $7.9 \%$ of the total expense, education accounted for $12 \%$, and saving accounted for 3.8\%. In the Vietnam study [13], medical expense accounted for $5.9 \%$ of the total expense, insurance accounted for $0.2 \%$, and there was not a separate category for saving. However, the "other" category which presumably included saving - accounted for only $4.6 \%$. In the Thailand study [6], medical cost accounted for $2 \%$ of the total expense, education accounted for $16 \%$, and there was not a separate category for saving. Factors that might contribute to the observed significant differences include the significant differences in total consumption (caused by an overall higher economic status), geographic differences, and rural-urban differences. Households surveyed in this study had a much higher rate of saving/investment. With regular savings, households may be able to cope with expenses caused by health shocks without reducing the cost of daily living [17].

In the analysis of illness conditions, negative associations between the presence of chronic disease and expenses on education and durable goods were observed. The reduction in consumption caused by illness has been observed in multiple studies $[4,5,13]$ and has an intuitive interpretation. However, it should be noted that the extension and magnitude of reduction were much smaller than those observed in published studies. Such a difference can be explained by the significantly higher economic status of Taiwanese households, which can be partly seen from the GDP figures. In the rural China study [5], the total household consumption was 2043.4RMB (less than 400USD; average household size unspecified). In the Vietnam study [13], the average household consumption for a household with $3.8 \mathrm{mem}$ bers was about 740USD. In contrast, in this study, 22.95\% of the total household expense was saving/investment. With a high saving rate, households would not need to reduce daily living costs to cope with illness conditions.

In the analysis of actual amount, most other expense categories were found not to be significantly associated with medical expense. This result suggested a relatively stable expenditure structure in response to illnessrelated financial shocks. The observed insensitivity differs from some published studies [5,13,17-19], in which both positive and negative associations between medical expense and other types of expenses had been observed. Again, such a difference can be explained by the higher income level and higher saving rate of Taiwanese households. Another possible reason is that Taiwan, unlike most regions and countries investigated in the aforementioned studies, offers universal health insurance coverage. The basic health insurance system in Taiwan has been applauded as a successful one. An effective health insurance system can protect households from reducing living costs because of illness. Additionally, the association between medical expense and entertainment was found to be positive and significant. However, the estimated regression coefficient is very small (0.008). We are not able to identify a logical interpretation for this association. We note that this result does not necessarily suggest any causation, and because of the small magnitude, the positive association should not be overinterpreted. The second set of analyses on expense percentage may better describe the scenario with a fixed budget, as the percentages summed to one. Although three significant associations were observed, the magnitudes measured by the odds ratios were small. The observed reductions in basic consumption and insurance were consistent with published studies $[5,13]$. When the percentage of medical expense increases, those of some other expenses have to decrease. Basic consumption and insurance together account for a big percentage of the total consumption and have room for reduction. The increase in the percentage of saving may reflect people's risk-averse nature and intention to protect from future health shocks.

\section{Limitations}

The survey response rate was $41.2 \%$, comparable to some published studies conducted in Taiwan [9]. With the phone call survey, we were not able to collect information from those who refused to participate. Thus, we cannot fully verify the "missing at random" condition. This may affect the quality of data. However, "eyeballing" summary statistics in Table 1 does not suggest any systematic bias of our samples. Our brief literature review fails to identify comparable studies to fully validate the quality of our data or otherwise. Ideally, longitudinal data is needed to fully track the changes in non-medical expenditures following illness conditions and estimate the impact of medical expenditure. In this study, only cross-sectional data was available, and some assumptions, such as stationarity, had to be made. An advantage of the phone call survey is that a large number of samples could be collected. However, a drawback is that interviewees had to recall the total amount of income and expenses for a period of 12 months. It has been suggested that such an approach may lead to a biased estimation (usually under estimation) [20]. A collection of other sources of data (for example medical records from hospitals for inpatient treatments) is needed to fully gauge the validity of survey measurements and correct any bias. However, with limited resources, such data was 
not available, and there is not a good way to fully evaluate the quality of the data. We note that many other survey studies share the same limitation. Illness condition was measured by the presence of chronic disease and inpatient treatment. Such measures did not take into account the type of illness and number of episodes. Of note, similar measures had been adopted in $[5,13]$ and others.

\section{Conclusion}

This study has provided an updated description of illness conditions and medical expenses and their associations with other consumptions. Some of the observations are new and informative. Specifically, studies conducted in other Asian regions and countries, including for example rural mainland China, Vietnam, and Thailand, suggested that illness conditions and medical expenditure had a significant negative impact on household consumption, particularly on basic consumption. In our study conducted in Taiwan, such a negative impact was not observed, and the findings were more positive. In general, in the surveyed population, households were able to cope with illness conditions and medical expenditure using means other than reducing other consumptions. On the other hand, the impact of illness and corresponding cost is still observable. Although the health insurance system in Taiwan has been generally recognized as very effective, there may be still room for improvement to further protect the financial wellness of the insured.

\section{Competing interests}

The authors declare that they have no competing interests.

\section{Authors' contributions}

SM and BS designed the study. KF, CM, and BS conducted the study. KF, JY and $Y L$ conducted statistical analysis. All authors read and approved the final manuscript.

\section{Acknowledgements}

We thank the editor and two reviewers for careful review and insightful comments, which have led to a significant improvement of the article. We thank all survey participants for their contributions.

\section{Funding}

The authors disclosed receipt of the following financial support for the research, authorship, and publication of this article: National Natural Science Foundation of China (Grant No. 71201139), Bureau of Statistics of China (Grant No. 2011LD002), and Yale MacMillan Center Faculty Research Grant. The funders have no role in study design, data analysis, manuscript preparation, and decision to submit.

\section{Author details}

'Department of Statistics, Xiamen University, Xiamen, China. ${ }^{2}$ Beijing Institute of Petrochemical Technology, Beijing, China. ${ }^{3}$ Department of Statistics and Information Science, FuJen Catholic University, New Taipei, Taiwan. ${ }^{4}$ School of Public Health, Yale University, 60 College ST, New Haven, CT 06520, USA.

\section{References}

1. Flores G, Krishnakumar J, O'Donnell O, Van Doorslaer E: Coping with health-care costs: implications for the measurement of catastrophic expenditures and poverty. Health Econ 2008, 17:1393-1412.

2. Foster A: Poverty and illness in low-income rural areas. Am Econ Rev 1994, 84:216-220.

3. Kabir MA, Rahman A, Salway S, Pryer J: Sickness among the urban poor: a barrier to livelihood security. J Int Dev 2000, 12:707-722.

4. Wagstaff $A$ : The economic consequences of health shocks: evidence from Vietnam. J Health Econ 2007, 26:82-100.

5. Wang $H$, Zhang L, Hsiao W: III health and its potential influence on household consumptions in rural China. Health Policy 2006, 78:167-177

6. Setboonsarng S, Lavado RF: Does organic agriculture lead to better health among organic and conventional farmers in Thailand? An investigation of health expenditure among organic and conventional farmers in Thailand. ADB Institute Working Paper No129; 2008.

7. Lu JR, Hisao WC: Does Universal health insurance make health care unaffordable? Lessons from Taiwan. Universal Coverage 2003, 22(3):77-88

8. Lee $S$, Chun C, Lee $Y$, Seo NK: The national health insurance system as one type of new typology: the case of South Korea and Taiwan. Health Policy 2008, 85(1):105-113.

9. Fang K, Shia BC, Ma S: Health insurance coverage, medical expenditure and coping strategy: evidence from Taiwan. BMC Health Serv Res 2012, $12: 442$.

10. Shih S, Ting C, Chang H, Kuo K: Insurance covered and non-covered complementary and alternative medicine utilization among adults in Taiwan. Soc Sci Med 2008, 67(7):1183-1189.

11. Kreng $V$, Yang $C$ : The equality of resource allocation in health care under the national health insurance system in Taiwan. Health Policy 2011, 100:203-210.

12. Liu TC, Chen CS: An analysis of private health insurance purchasing decisions with national health insurance in Taiwan. Soc Sci Med 2002, 55:755-774.

13. Nguyen K, Khuat OTH, Ma S, Pham DC, Khuat GTH, Ruger JP: Effect of health expenses on household capabilities and resource allocation in Vietnam. PLoS One 2012, 7(10):e47423.

14. Waksberg J: Sampling methods for random digit dialing. J Am Stat Assoc 1978, 361:40-46

15. Hosmer DW, Lemeshow S: Applied logistic regression. New York: Wiley; 2000.

16. Fang $K$, Jiang $Y$, Shia BC, Ma S: Impact of illness and medical expenditure on household consumptions: a survey in western China. PLoS One 2012, 7(12):e52928.

17. Fang K, Shia BC, Ma S: Health insurance coverage and impact: a survey in three cities in China. PLoS One 2012, 7(6):e39157.

18. Kopecky KA, Koreshkova T: The impact of medical and nursing home expenses and social insurance policies on savings and inequality. Federal Reserve Bank of Atlanta; 2010. Working paper 2010-19.

19. van Doorslaer E, O'Donnell O, Rannan-Eliya RP, Somanathan A, Adhikari SR, Garg CC, Harbianto D, Herrin AN, Huq MN, Ibragimova S, Karan A, Lee TJ, Leung GM, Lu JF, Ng CW, Pande BR, Racelis R, Tao S, Tin K, Tisayaticom K, Trisnantoro L, Vasavid C, Zhao Y: Catastrophic payments for health care in Asia. Health Econ 2007, 16:1159-1184.

20. Lu C, Chin B, Li G, Murray CJL: Limitations of methods for measuring out of pocket and catastrophic private health expenditures. Bull World Health Org 2009, 87:238-244.

doi:10.1186/1471-2458-13-743

Cite this article as: Fang et al:: Illness, medical expenditure and household consumption: observations from Taiwan. BMC Public Health 2013 13:743. 